Journal of Organometallic Chemistry, 282 (1985) 127-131

Elsevier Sequoia S.A., Lausanne - Printed in The Netherlands

\title{
THE METALLATION OF $\boldsymbol{N}, \boldsymbol{N}$-DIMETHYLAMINOTOLUENE BY PALLADIUM ACETATE. EVIDENCE FOR A TRINUCLEAR SPECIES
}

\section{MICHEL PFEFFER*,}

Laboratoire de Chimie de Coordination, Université Louis Pasteur, 4 rue Blaise Pascal, F-67070 Strasbourg Cedex (France)

ERIK WEHMAN and GERARD VAN KOTEN

Universiteit van Amsterdam, Anorganisch Chemisch Laboratorium, J.H. van't Hoff Instituut, Nieuwe Achtergracht 166, $1018 \mathrm{WV}$ Amsterdam (The Netherlands)

(Received September 10th, 1984)

\section{Summary}

The reaction of cis or trans $\mathrm{di}(\mu$-chloro)bis $\{[2-($ dimethylamino)phenyl]methyl $\} \mathrm{di}-$ palladium with silver acetate affords the corresponding trans dimeric compound with two acetato bridges between the palladium atoms. The molecule is non-rigid in solution. A closer investigation of the product obtained previously from the reaction of the toluidine ligand (dmatH) with palladium acetate in acetic acid, shows that it is a trinuclear species of general formula $\mathrm{Pd}_{3}(\mathrm{dmat})_{2}\left(\mu_{2}-\mathrm{O}_{2} \mathrm{CCH}_{3}\right)_{4}$, similar to species observed in palladation of olefins by palladium acetate.

\section{Introduction}

A large number of ligands containing a Group V or VI donor atom have been successfully metallated by using palladium acetate as the starting material. To the best of our knowledge in all cases the compounds obtained were shown to be dinuclear molecules with two acetato bridging units between the palladium atoms [1]. Recently one of us reported the cyclopalladation by a similar reaction of the 2-dimethylaminotoluene ligand (dmatH) [2]. A dimeric structure was also assigned to $\mathrm{Pd}_{3}(\mathrm{dmat})_{2}\left(\mu_{2}-\mathrm{O}_{2} \mathrm{CCH}_{3}\right)_{4}$ (1) thus produced. However, the true nature of 1 remained uncertain for the following reasons: (i) its ${ }^{1} \mathrm{H}$ and ${ }^{13} \mathrm{C}$ NMR spectra were more complicated than those of related species, since the acetato gave rise to multiple resonances which were unexplained for a simple species; (ii) the metathesis reaction between the acetato bridges and halides afforded only a low yield of the chloride bridged compound cis- and trans-[Pd(dmat)Cl $]_{2}(2)$, a result that would be unexpected if the dimeric formula for 1 were correct. We now describe a reinvestigation of the formulation of 1 , which was prompted by the synthesis of the true dimeric acetato bridged species. 


\section{Results and discussion}

Treatment of a solution of cis- and trans-[Pd(dmat) $\mathrm{Cl}_{2}$ (2) with silver acetate affords yellow crystals of compound 3 (see eq. 1) whose analytical and spectroscopic data are consistent with a dinuclear species in which two acetato groups bridge the palladium atoms. The carboxylate absorptions in the infrared spectrum, at 1580 and $1412 \mathrm{~cm}^{-1}$, are characteristic of bridging acetato groups, and exclude the possibility of a mononuclear species [3].

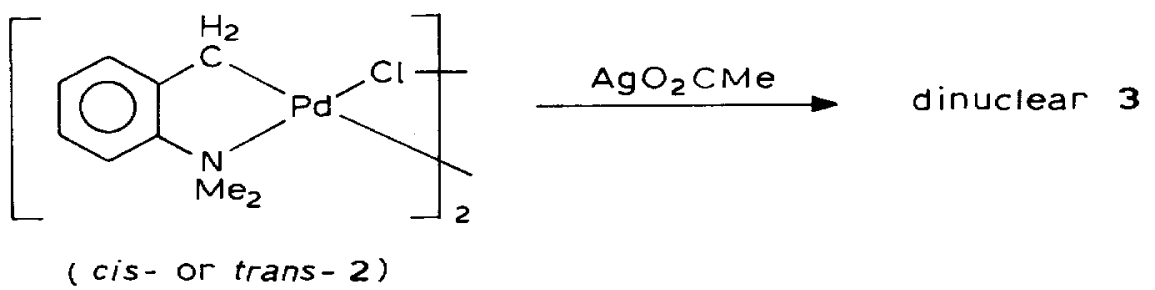

The ${ }^{1} \mathrm{H}$ NMR spectrum at $-30^{\circ} \mathrm{C}$ (see Experimental section) shows a single resonance for the methyl group of the acetato ligand, two peaks for the methyls of the $\mathrm{NMe}_{2}$ moiety, and a four line $A B$ type pattern for the $\mathrm{CH}_{2}$ group. These results indicate that (i) 3 exists in only one isomeric form, and (ii) no plane of symmetry containing the nitrogen or the carbon atoms of the $\mathrm{NMe}_{2}$ and the $\mathrm{CH}_{2}$ groups is present in the molecule. This feature is consistent with a dimeric molecule with two acetato bridges [1] since in these molecules the coordination planes of the palladium atoms are almost parallel to each other, the $\mathrm{Pd} \cdot$.. Pd distance being relatively short [1d]. We believe that 3 is probably the trans isomer, because for the cis isomer one would expect severe interactions between the two closest methyl groups of the $\mathrm{NMe}_{2}$ moieties; the Pd ...Pd distance in these molecules is usually close to $2.9 \AA$, and in this case such a separation is too short to allow two $\mathrm{NMe}_{2}$ groups to be in a cis position. At room temperature the signals of the $\mathrm{NMe}_{2}$ and the $\mathrm{CH}_{2}$ protons broaden, and they coalesce at ca. $35^{\circ} \mathrm{C}$. Each signal gives rise to a broad singlet which accidently coincide at $3.19 \mathrm{ppm}$. Above $45^{\circ} \mathrm{C}$ this signal begins to sharpen, but the fast exchange limit could not be reached. To account for this temperature dependence of the ${ }^{1} \mathrm{H}$ NMR spectrum, compound 3 must be non-rigid in solution, and rapid inversion of the dimer is thought to occur as in the process depicted in Fig. 1. The mechanism of the inversion of this eight-membered ring has been studied
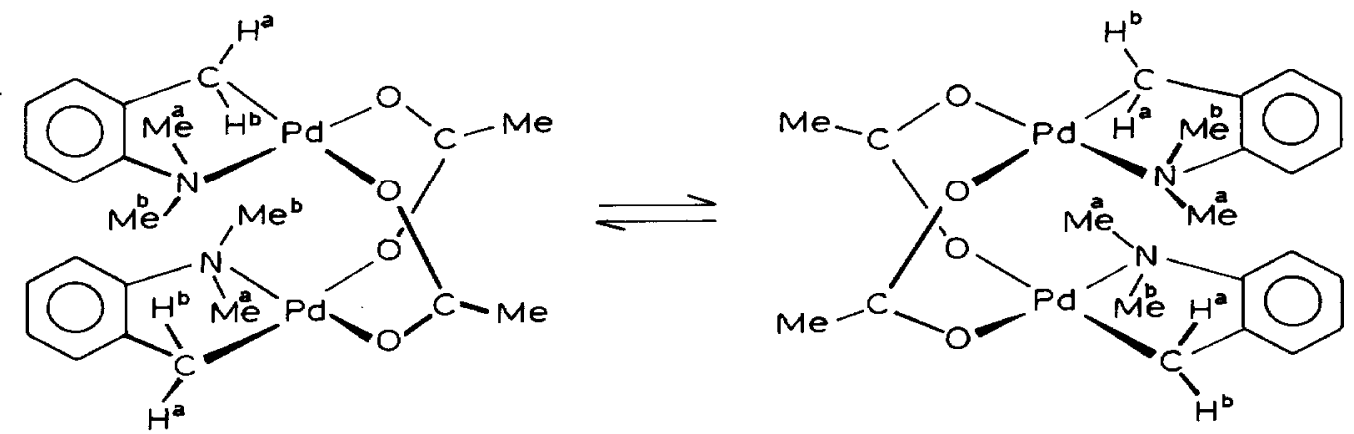

Fig. 1. Dynamic behaviour of complex 3 . 
previously, and so we did not study our system in more detail [4].

The ${ }^{13} \mathrm{C}$ NMR spectrum of 3 at room temperature is consistent with all these conclusions since all carbon atoms including those of the $\mathrm{NMe}_{2}$ group are observed as singlet resonances.

These results indicate that compound 1 is not a dimeric molecule, and this prompted us to reinvestigate this compound. It was obtained by the reaction of dmatH with palladium acetate in acetic acid and crystallized from $\mathrm{CH}_{2} \mathrm{Cl}_{2}$, the crystals containing some of that solvent. The analysis of all the elements of that species are in accord with a molecule in which the ligand to acetato ratio is $1 / 2$ instead of $1 / 1$. The molecular ion peak of $m / e=824$ in the FD mass spectrum is consistent with a trinuclear molecule. In the light of the ${ }^{1} \mathrm{H}$ and the ${ }^{13} \mathrm{C} N M R$ spectra we propose the following structure for 1 (see eq. 2):
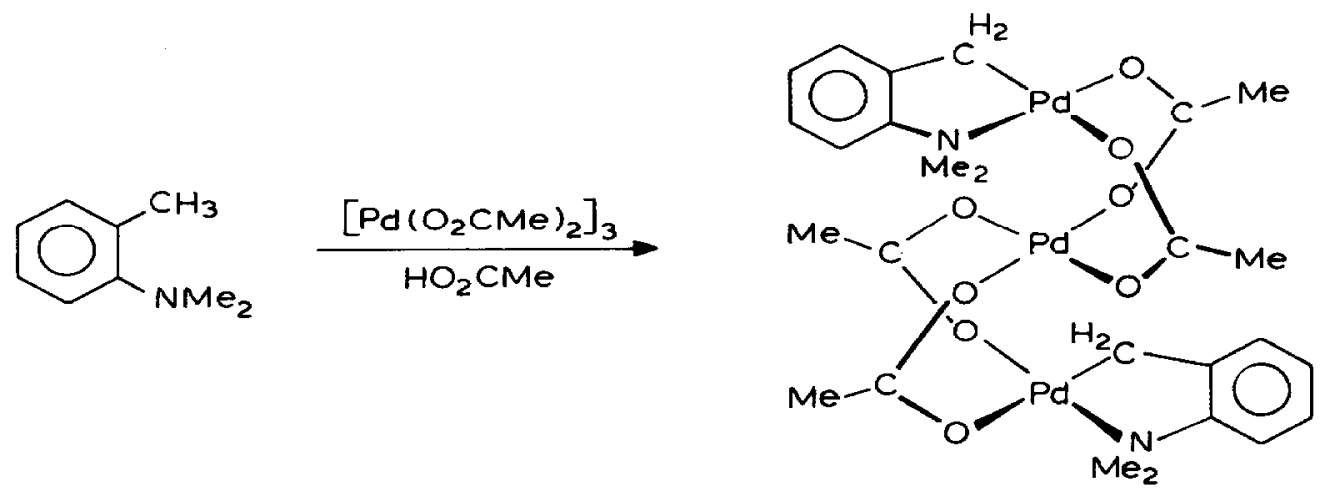

(cis - or trans - 1 )

The ${ }^{1} \mathrm{H}$ NMR spectrum [2] shows four anisochronous acetato resonances, which point to the presence of two isomers. In the structure shown in eq. 2 the two $\mathrm{N}$ atoms can be positioned either on the same side of the molecule $(c i s-\mathrm{N})$ or on opposite sides (trans-N). Both isomers give rise to two distinct acetate methyl resonances. The appearance of these four distinct peaks indicate that there is no interconversion, on the NMR time scale, between the cis and the trans isomers. As for 3 the two methyls of the $\mathrm{NMe}_{2}$ groups in 1 are diastereotopic, and so two singlets are observed for these protons. The two isomers together give rise to four methyl resonances, and these partly coïncide to give three peaks of unequal height. The conclusions drawn from these ${ }^{1} \mathrm{H}$ NMR studies are confirmed by the ${ }^{13} \mathrm{C}$ NMR spectrum [2].

This is the first time that the metallation of a ligand containing a nitrogen or a sulfur as the donor atom by trimeric palladium acetate has been found to give such a trinuclear species [1]. On the other hand it is well known that substituted olefines can be metallated to give $\pi$-allylic systems of this type if the palladation is carried out in acetic acid [5]. Recently, a crystal structure analysis was described for such a compound [6]. In our case, the formation of the trimetallic species 1 cannot be accounted for by the fact that the reaction was carried out in acetic acid [2], since we obtained the same result when the palladation of the dmatH ligand was performed in another solvent, such as dichloromethane. Moreover numerous cyclopalladation reactions have been successfully carried out in acetic acid [1a], and in all cases a dimeric compound was obtained. We suggest that the mechanism of the palladation 
of the dmatH is likely to resemble that of olefinic ligands, at least in the early steps of the reaction, though in the final product the coordination of the nitrogen lone pair is probably involved, to give a five-membered ring including the metal. However, the fact that in solution the $\mathrm{NMe}_{2}$ methyl groups in $\mathbf{1}$ are diastereotopic indicates that the $\mathrm{N}$ centers have a stable pyramidal geometry. This can only arise from $\mathrm{Pd}-\mathrm{N}$ coordination which is inert on the ${ }^{1} \mathrm{H}$ and ${ }^{13} \mathrm{C}$ NMR time scales [7]. Unfortunately we have not yet been able to obtain crystals suitable for an X-ray study to confirm the trinuclearity of 1 .

\section{Experimental}

The ${ }^{1} \mathrm{H}$ and ${ }^{13} \mathrm{C}$ NMR spectra were recorded on a Bruker WM 250 or a Bruker SY 200 spectrometer. The field desorption mass spectrum was obtained with a Varian MAT 711 double focussing mass spectrometer equipped with a combined EI/FI/FD ion source and coupled to a spectrosystem MAT 100 data acquisition unit. The sample was dissolved in methylene chloride and then transferred to the emitter by the dipping technique. Elemental analyses were carried out at the Institute for Organic Chemistry T.N.O. (Utrecht, The Netherlands) and by the Service Central de microanalyse du C.N.R.S. (Strasbourg, France).

$\mathrm{Pd}_{3}(\mathrm{dmat})_{2}\left(\mu-\mathrm{O}_{2} \mathrm{CCH}_{3}\right)_{4}(1)$ and $[\mathrm{Pd}(\mathrm{dmat})(\mu-\mathrm{Cl})]_{2}(2)$ were synthezised as published [1].

$\left[\mathrm{Pd}_{3}\left(2-\mathrm{NMe}_{2} \mathrm{C}_{6} \mathrm{H}_{4} \mathrm{CH}_{2}\right)_{2}\left(\mu-\mathrm{O}_{2} \mathrm{CCH}_{3}\right)_{4}\right] \cdot 1.4 \mathrm{CH}_{2} \mathrm{Cl}_{2}(\mathrm{I})$

(Found: $\mathrm{C}, 34.67 ; \mathrm{H}, 4.09 ; \mathrm{N}, 2.94 ; \mathrm{O}, 13.84 ; \mathrm{Cl}, 10.34 ; \mathrm{Pd}, 33.55$. $\mathrm{C}_{26} \mathrm{H}_{36} \mathrm{~N}_{2} \mathrm{O}_{8} \mathrm{Pd}_{3} \cdot 1.4 \mathrm{CH}_{2} \mathrm{Cl}_{2}$ calcd.: C, 34.91; H, 4.14; N, 2.97; O, 13.58; Cl, 10.53; $\mathrm{Pd}, 33.87 \%$ ).

FD-mass spectral results: $m / e$ values of observed peaks (rel. int.): $818(6.5)$; 819(12.0); 820(17.5); 821(35.0); 822(56.5); 823(66.0); 824(100); 825(99.0); 826(91.0); $827(55.0) ; 828(61.0) ; 829(41.0) ; 830(32.0) ; 831(25.0) ; 832(27.0)$.

$\left.\left[\overparen{P d\left(2-\mathrm{NMe}_{2} \mathrm{C}_{6} \mathrm{H}_{4} \mathrm{CH}\right.} \mathrm{H}_{2}\right)\left(\mu-\mathrm{O}_{2} \mathrm{CCH}_{3}\right)\right]_{2}$ (3)

An excess of silver acetate $(171 \mathrm{mg}, 1 \mathrm{mmol})$ was added to a well-stirred solution of $2(138 \mathrm{mg}, 0.25 \mathrm{mmol})$ in acetone $(30 \mathrm{ml})$ at room temperature. After $24 \mathrm{~h}$ the yellow solution was filtered, to remove $\mathrm{AgCl}$ and the excess of silver acetate, then dried in vacuo. Crystallisation of the product from $\mathrm{CH}_{2} \mathrm{Cl}_{2} /$ pentane gave 3 as yellow crystals $(100 \mathrm{mg}, 66 \%)$.

(Found: $\mathrm{C}, 44.37 ; \mathrm{H}, 5.13 ; \mathrm{N}, 4.88 . \mathrm{C}_{22} \mathrm{H}_{30} \mathrm{~N}_{2} \mathrm{O}_{4} \mathrm{Pd}_{2}$ calcd.: $\mathrm{C}, 44.08 ; \mathrm{H}, 5.01 ; \mathrm{N}$, 4.68\%).

${ }^{1} \mathrm{H}$ NMR $\left(\mathrm{CDCl}_{3}\right)-30^{\circ} \mathrm{C}: 7.03\left(\mathrm{~s}, \mathrm{br}, 4 \mathrm{H}, \mathrm{C}_{6} \mathrm{H}_{4}\right), 3.25$ and 2.77 (dd, $2 \mathrm{H}, A B$ type pattern, $\left.\mathrm{CH}_{2},{ }^{2} J\left(H^{A} H^{B}\right) 14.04 \mathrm{~Hz}\right), 3.22\left(\mathrm{~s}, 3 \mathrm{H}, \mathrm{NCH}_{3}\right), 3.04\left(\mathrm{~s}, 3 \mathrm{H}, \mathrm{NCH}_{3}\right)$ and $1.95 \mathrm{ppm}\left(\mathrm{s}, 3 \mathrm{H}, \mathrm{CH}_{3} \mathrm{CO}_{2}{ }^{-}\right)$.

${ }^{13} \mathrm{C}$ NMR $\left(\mathrm{CDCl}_{3}\right): 181.5(\mathrm{~s}, \mathrm{O}-\mathrm{C}-\mathrm{O}), 156.4,146.1,128.9,127.8,126.1,119.4(\mathrm{~s}$, aromatic C), $53.8\left(\mathrm{~s}, 2 \mathrm{C}, \mathrm{N}\left(\mathrm{CH}_{3}\right)_{2}\right), 24.4\left(\mathrm{~s}, \mathrm{CH}_{3} \mathrm{CO}_{2}\right)$ and $19.65 \mathrm{ppm}\left(\mathrm{s}, \mathrm{CH}_{2} \mathrm{Pd}\right)$.

\section{References}

1 (a) J.M. Thompson and R.F. Heck, J. Org. Chem., 40 (1975) 2667; (b) R. Rüger, W. Rittner, P.G. Jones, W. Isenberg and G.M. Sheldrick, Angew. Chem. Int. Ed. Engl., 20 (1981) 382; (c) A.J. Deeming 
and I.P. Rothwell, J. Organomet. Chem., 205 (1981) 117; (d) M.R. Churchill, H.J. Wassermann and G.J. Young, Inorg. Chem., 19 (1980) 762; (e) K. Hiraki, Y. Fuchita, and K. Takechi, Inorg. Chem., 20 (1981) 4316.

2 J. Dehand, C. Mutet and M. Pfeffer, J. Organomet. Chem., 209 (1981) 255.

3 T.A. Stephenson, S.M. Morehouse, A.R. Powell, J.P. Heffer and G. Wilkinson, J. Chem. Soc. A, (1965) 3632.

4 J. Powell, J. Amer. Chem. Soc., 91 (1969) 4311; J. Powell and T. Jack, Inorg. Chem., 11 (1972) 1039; P.W.N.H. Van Leeuwen and A.P. Praat, Rec. Trav. Chim. Pays-Bas, 89 (1970) 321.

5 R.G. Brown, R.V. Chandhari and J.M. Davidson, J. Chem. Soc., Dalton Trans., (1977) 176.

6 L.Yu. Ukhin, N.A. Dolgopolova, L.G. Kuz'mina and Yu.T. Struchkov, J. Organomet. Chem., 210 (1981) 263.

7 A.F.M.J. van der Ploeg, G. van Koten, K. Vrieze and A.L. Spek, Inorg. Chem., 21 (1982) 2014 and references cited therein. 